\title{
Elucidating Forms of Life. The Evolution of a Philosophical Tool
}

\section{Abstract}

Although the expression "form of life" and its plural "forms of life" occur only five times in Pbilosophical Investigations, and generally few times in his works, it is commonly agreed that this is one of the most important issues in Wittgenstein's later philosophy. Starting from the analysis of the contexts in which Wittgenstein makes use of this concept, the paper focuses on the different interpretations that have been given in the secondary literature, and proposes a classification based on two axes of debate: the monistic versus pluralistic interpretation, and the empirical versus transcendental interpretation. After placing some well-known readings in the resulting scheme, an attempt will be made to offer an evolutionary reading of Wittgenstein's own ideas about forms of life. It will be argued that the empirical and plural view that seems characteristic of his writings in the 1930s, slowly appears to turn towards a monistic view, sometimes with transcendental tones, although within a pragmatic perspective. This turn nevertheless remains rooted in Wittgenstein's general attitude towards philosophy intended as a conceptual inquiry with clarifying and therapeutic aims.

\section{Introduction}

One of the most debated concepts of Wittgenstein's later philosophy is that of form of life, or, as we should say following his 
own suggestion ${ }^{1}$, way of living. Although Wittgenstein makes use of it only on a few occasions, many interpretations have been offered for this key notion. This paper aims to disentangle some of the confusions characterizing the debate by highlighting the presence of two axes of dispute, which should be kept distinguished: the monistic versus pluralistic readings, and the empirical versus transcendental readings. A closer look at Wittgenstein's texts will then bring to light the existence of an evolution in the philosopher's own idea of form of life. The paper seeks to contextualize this evolution in the broader framework of Wittgenstein's general attitude towards the activity of philosophy.

I will proceed as follows. Section 1 is exegetical: I will consider the five occurrences of the expression Lebensform/Lebensformen in Philosophical Investigations $^{2}$, and trace them back to their original formulations in the Nachlass. We shall see some possible contrasting interpretations of the concept begin to emerge. Section 2 will focus on the secondary literature, considering some of the most relevant readings, including those of J. F. M. Hunter, Max Black, Stanley Cavell, Ernst Gellner, Bernard Williams, Naomi Scheman, Jonathan Lear, Norman Malcolm. In section 3, I will propose a classification of these readings of Wittgenstein's ideas, based on a crossing of the two mentioned axes: the monistic versus pluralistic and the empirical versus transcendental interpretations. The analytic instrument thus acquired will help us to get back to Wittgenstein's texts with more precision. In section 4, other occurrences of the term will be considered, both previous and subsequent with respect to the PI entries; this exploration will show that Wittgenstein's own ideas underwent an evolution, from a pluralistic and empirical view, towards a monistic and, for some aspects, transcendental view. Nevertheless, I will argue, this development is not the development from a sort of empiricism to a sort of transcendentalism. Wittgenstein seems not to be interested in asserting what forms of life are. This concept is never a

\footnotetext{
${ }^{1}$ See Section 2 below.

${ }^{2}$ Hereafter, PI. Quotes are from Hacker and Schulte's revised fourth edition, 2009. Accordingly, what is traditionally known as the second part of PI is here abbreviated as PPF (Philosophy of Psychology - a Fragment).
} 
substantive idea but remains a philosophical tool, a part of Wittgenstein's way of conceiving philosophical activity, aimed at directing our attention to the belonging of words and sense to the broader horizon of life itself.

\section{Forms of life in Philosophical Investigations}

In PI, we meet the expression 'Lebensform' five times. Each of these entries can be briefly traced back to its original formulation.

(1) It is easy to imagine a language consisting only of orders and reports in battle. - Or a language consisting only of questions and expressions for answering Yes and $\mathrm{No}-$ and countless other things. And to imagine a language means to imagine a form of life [Lebensform] (PI 19).

The first formulation of this idea, as well as - as far as I know - the first occurrence of the word "Lebensform" in Wittgenstein's writings, can be found in the second part of MS 115, which is a 1936 German revision of the Brown Book. ${ }^{3}$ Here we can read:

(1a) Let us imagine a linguistic use (a culture) in which there is a common name for green and red, and one for blue and yellow. [...] I could also think of a language (and this means again a form of life [eine Lebensform/Forms des Lebens]), which establishes a chasm between dark red and light red. (MS 115, 238-239) ${ }^{4}$

In the Brown Book (1934-1935), which as we know was in English, Wittgenstein had used only "culture" and, in connection therewith, "tribe" instead of the expression "form of life":

(1b) Imagine a use of language (a culture) in which there was a common name for green and red on the one hand and yellow and blue on the other [...]. We could also easily imagine a language (and that means again a culture) in which there existed no common expression for light blue and dark blue, in which the former, say, was called 'Cambridge', the latter 'Oxford'. If you ask a man of this tribe what

\footnotetext{
${ }^{3}$ It must be noted however that according to recent research by Arthur Gibson, the text on which Wittgenstein worked for MS 115 was probably not the Brown Book as we know it, but another notebook that Wittgenstein dictated to Francis Skinner in those years. Cf. Pichler, Smith (2013: 311 n. 3).

${ }^{4}$ Texts from the manuscripts are from BEE; translations are mine, except for the parts which also appear in Wittgenstein's published writings.
} 
Cambridge and Oxford have in common, he'd be inclined to say 'Nothing' (BB, 134-135)'.

Thus, in introducing the concept of form of life, what Wittgenstein had in mind was the culture of different (imaginary) tribes. Let us go to the second occurrence in PI.

(2) But how many kinds of sentence are there? Say assertion, question, and command? - There are countless kinds: countless different kinds of use of all the things we call "signs", "words", "sentences". And this diversity is not something fixed, given once for all; but new types of language, new language-games, as we may say, come into existence, and others become obsolete and get forgotten. (We can get a rough picture of this from the changes in mathematics.)

The word "language-game" is used here to emphasize the fact that the speaking of language is part of an activity, or of a form of life [Lebensform $]$ (...) (PI 23).

The original formulation of this entry is to be found in MS 142 (p. 20, last months of 1936):

(2a) The term "language game" is (here) meant to bring into prominence the fact that the speaking of a language is a determinate process [Teilvorgang] / part of a form of activity / of an activity or of a form of life [Lebensform];

where the word Lebensform has been subsequently added.

It is interesting to notice that in correcting Rush Rhees' translation of (1) and (2) in the early version of the PI (1939), Wittgenstein explicitly "authorized" the use of the expression "way of living" to translate Lebensform, and for (2) added: "of human beings" (TS 226, 10, 15). This aspect has been noticed by Gier (1980: 251), Fischer (1987: 40) and Garver (1994a: 248), who cites Fischer as his source. Fischer speaks of "way of life", Gier and Garver of "ways of life", while in the Nachlass, we can read, more precisely, "way of living".

\footnotetext{
5 The difference between the Brown Book and MS 115 is the starting point of Biancini (2011), who offers an interesting genealogical reading of the concept of form of life, though strangely without noticing that the first occurrence of the term Lebensform is in MS 115 itself.
} 
The third occurrence of the term in PI has to do with the concept of agreement:

(3) "So you are saying that human agreement decides what is true and what is false? - What is true or false is what human beings say; and it is in their language that human beings agree. This is agreement not in opinions, but rather in form of life [Lebensform] (PI 241).

The difference between agreement in opinion and agreement in form of life first appears in 1938, and it follows some remarks about rules:

(3a) 'How is the application of a rule fixed?' - Do you mean, 'logically' fixed? Either through other rules, or nothing at all. - Or do you mean: how is it, that we all apply it in agreement in this way and not otherwise? By training, discipline, and the forms of our life [die Formen unsres Lebens]. It is not a consent of opinion, but of forms of life [Lebensformen] (MS 160, 26).

The latter two entries of the term in PI belong to PPF and were formulated later, in the second half of the 1940s. The fourth occurrence is inspired by a comparison with an animal form of life:

(4) (...) A dog believes his master is at the door. But can he also believe that his master will come the day after tomorrow? - And what can he not do here? - How do I do it? - What answer am I supposed to give to this?

Can only those hope who can talk? Only those who have mastered the use of a language. That is to say, the manifestations of hope are modifications of this complicated form of life [Lebensform]. (If a concept points to a characteristic of human handwriting, it has no application to beings that do not write.) (PPF 1)

The original source is MS 137, where we can read:

(4a) Can only those hope who can talk? Only those who have mastered the application of a language. The signs of hope are modes of a complicated pattern of life [Lebensmuster] (variant: pattern [Muster]) (MS 173, 115a; later published in LWP I 365. See also RPP II 308-310)

The fifth and last entry is perhaps the best known and the most debated, as it is connected with the seemingly problematic concept of "the given": 
(5) What has to be accepted, the given, is - one might say - forms of life [Lebensoformen]. (PPF 345)

In a different formulation of this last remark, dated November 1946, a practical and anthropological aspect is more explicit:

(5a) Instead of the unanalysable, specific, indefinable: the fact that we act in such-and-such ways, e.g. punish certain actions, establish the state of affair thus and so, give orders, render accounts, describe colours, take an interest in others' feelings. What has to be accepted, the given - it might be said - are forms of life [Lebensformen] (Variant: facts of living [Tatsachen des Lebens]). (MS 133, 28r; then with secondary variations in RPP I 630)

There are a few other occurrences of the term Lebensform/Lebensformen in Wittgenstein's works besides these five entries in the PI, but we shall leave them out for now and move on to a short survey of the different interpretations in the secondary literature, focused mostly on PI.

\section{Interpretations of forms of life}

From the five occurrences which we have listed, some (apparently) uncontroversial features can be pointed out: forms of life are associated with language; they are, or are connected to, a sort of activity; they are the ground on which human beings agree, and they are "what has to be accepted". However, already on the basis of these features, doubts and uncertainties arise. The first one is evident: is there one single form of life, as we could imagine from the standpoint of (4), or are there more forms of life, as we could argue from the link between activities and forms of life established in (2) and from the use of the plural form in (5)? This is indeed one of the most discussed controversies, and we can start from here to explore the secondary literature in some detail. Needless to say, the following positions represent only a part - but, I hope, a good sample - of the existent literature.

One of the earliest and most influential readings is offered by J. F. M. Hunter (1968), who lists four alternative interpretations: 1) form of life is a linguistic game; 2) it is a package of types of behaviour; 3) it is a life-style, in a historical-cultural sense; 4) it is something typical of a living being. It is this last interpretation that 
Hunter finally espouses, calling it "the organic account", and specifying that form of life is a biological, individual characteristic of each human being.

A different view is proposed by Max Black (1978), who, like Hunter, examines the five occurrences in the PI, and concludes that the expression Lebensform is applied to an activity, meant as including anything necessary for producing meaningful and sensible utterances. In this way, he connects the mastery of sub-languages to particular forms of life, on the one hand restricting the field (a language game, and thus a form of life, is something particular), on the other hand enlarging it (there are more, different, forms of life, entangled by different sub-languages).

Nicholas Gier (1980: 245) offers a complex definition, according to which the concept of Lebensformen is developed in terms of four levels:

1) a biological level from which 2) unique human activities like pretending, grieving etc. are then expressed in 3) various cultural styles that in turn have their formal ground in a 4) general socio-linguistic framework (Wittgenstein's Weltbild).

Gier thinks of Lebensformen as specific activities and attitudes proper of mankind, like hoping, or believing in the Last Judgement, or being certain, but he also holds that the concept is not to be taken as a "factual theory": forms of life, he says, "perform a transcendental function" (ibid:: 257).

Stanley Cavell, like Hunter, is inclined toward a biological account, which he defines as "vertical" and distinguishes from the "horizontal" dimension of cultural differences (Cavell 1979: 83; Cavell 1989: 41-42). He also explains that the fifth PI entry - on forms of life that must be accepted as "the given" - if read in a superficial political perspective, contributes to the idea that Wittgenstein is conservative, because it seems as if he invited us to accept social practices as they are. According to Cavell, instead, Wittgenstein wants us to look for our vital requirements as human beings and, in so doing, to turn the whole examination round, rotating its axis of reference about the pivot of "our real need" (cf. PI 108). 
The aim to connect forms of life to different cultural/social/political traditions or systems has indeed lead some commentators to propose a relativistic and, for some of them, conservative perspective. This is the case, for example, of Ernest Gellner, who in Reason and Culture depicts the later Wittgenstein as an exponent of irrationalism, advocate of the Gemeinschaft and of its consequent "cultural idiosyncrasies" (1992: 116-124; see also 1985). But for other interpreters, relativism is not to be read as leading to conservatism. Kathleen Emmett (1980), for example, challenges the idea that forms of life alternative to ours would not be thinkable or viable. She insists on the fact that forms of life can change in a biographical, historical and geographical sense. Change is also a crucial theme for Naomi Scheman (1996), who underlines that the impossibility of seeing things independently from our own position and interests does not prevent us from being able to have a critical attitude towards our form of life and to promote change. This is possible by placing ourselves within, but somewhere on the margins of a form of life: it is the presence of different standpoints that makes objectivity itself possible.

Emmett and Scheman, stressing the importance of our not going on in the same way in many things, both cite the Kantian position represented by Jonathan Lear as an adversary. In Lear's opinion, forms of life are, on the one hand, an object, as we can see and describe them; on the other, a transcendental "I think", or a "We think", or a "We are so minded", and in this sense they should not be treated as predicates: they are what makes any description possible at all (Lear 1984, 1986). Lear affirms that the two meanings of forms of life can and must be kept together in a sort of "transcendental anthropology", and that this is what Wittgenstein tries to do. The Kantian background is to be found also in Bernard Williams' account, according to which the later Wittgenstein's form of life is a "pluralization" of the transcendental subject of the Tractatus. If, for the early Wittgenstein, "the limits of my language mean the limits of my world", for the later Wittgenstein, Williams adds, "the limits of our language mean the limits of our world” (1974: 82). 
Another well-known perspective, which opposes that of Bernard Williams, is offered by Malcolm (1982), who notices that every time Wittgenstein uses the term "we", he is speaking about a definite group of people. The fact that we can understand other groups only through our own language and way of seeing, Malcolm holds, does not entail any form of idealism and hence there is no point in comparing the later and the early Wittgenstein on this account. ${ }^{6}$ Working on both Williams and Lear, Lynne Rudder Baker (1984) concludes, conversely, that through form of life Wittgenstein offers a transcendental argument to make sense of the idea of meaning, and that forms of life should be interpreted neither as empirical regularities (the mistake she imputes to Hilary Putnam) nor as arbitrary decisions on vocabulary (the opposite mistake, which she imputes to Richard Rorty).

An interesting middle position between transcendentalism and naturalism is offered by Newton Garver (1994a, 1994b), who affirms that there is one single human form of life, with different linguistic games belonging to it. The only forms of life different from ours are those of animals and of the fictitious communities that Wittgenstein repeatedly invites us to imagine. The grounds of form of life, defined as "requirements of our understanding anything at all" (1994b: 48, 61) - Garver argues - are to be found in natural history, which includes not only biology but also the cultural side of human behaviour. ${ }^{7}$

According to Anne-Marie Christensen (2011), neither relativism nor transcendentalism are able to give accurate accounts of Wittgenstein's writings: the former because it fails to acknowledge that for Wittgenstein natural history provides a common background for any cultural form of life; the latter because it reshapes Wittgenstein's "modest objectivity" into transcendental necessity. A way out, she argues, is offered by Peter Winch, often

\footnotetext{
${ }^{6}$ See also Malcolm (1986: 238) and (1966: 91-92). Another fruitful and more recent critique of the idealist position is Cerbone (2011).

${ }^{7}$ It must be said that Garver's concept of transcendentality is quite peculiar, as he on the one hand does not clearly distinguish it from transcendence, on the other connects it strictly to natural history; see Garver (1994b, 44, 62, 65).
} 
grouped alongside relativists or conventionalists, ${ }^{8}$ because he affirms that any standard of intelligibility is established within a culturally shaped life-form. But Winch also underlines that the very conception of human life involves fundamental notions such as those of birth, death, sexual relations; these notions are not transcendental ${ }^{9}$ but are "deep objects of human concern", and they provide the starting point for an understanding of the life of other cultures. This understanding requires the widening and the extension of our own way of life (Winch 1964: 317-318). ${ }^{10}$

\section{Avoiding conceptual confusion}

This brief but quite dense overview might seem perplexing. How is it possible that a single notion, on which Wittgenstein himself wrote so little, can generate so many and so different interpretations?

To some extent, the different opinions I have mentioned can coexist, because in Wittgenstein's own texts there is not one single view (cf. Biancini 2011: 121). Similar remarks could be made in respect to Wittgenstein's characterization of "hinges", to use the expression now commonly adopted by commentators, in $\mathrm{On}$ Certainty. Hinges are the basic certainties which shape our Weltbild, our image of the world. They are those certainties which, usually unnoticed, allow our practices and linguistic games to work. As Danièle Moyal-Sharrock (2004: ch. 5) has shown, they belong to different domains: there can be linguistic hinges, personal hinges, local hinges, universal hinges. Similarly, forms of life can have more than one dimension, and the fact that Wittgenstein's own examples cover more aspects should not be a surprise.

In order to avoid conceptual confusion, in any case, it might be of profit to notice that there are two axes of debate on forms of life, which should be kept distinguished. One is the monistic vs.

\footnotetext{
${ }^{8}$ See for instance Witherspoon (2003).

${ }^{9}$ According to Hertzberg (1980), Winch does consider our concern with these notions as transcendental.

$10 \mathrm{I}$ am not considering here the peculiar notion of forms of life used in Winch (1958). On Winch (and Wittgenstein) as non-relativistic and non-conservative, see also Pleasants (2000).
} 
pluralistic axis, the other the empirical vs. transcendental axis. It would be easy to identify the empirical reading with the plural view (there are different forms of life, different cultures, to be found empirically in the world); and the transcendental reading with a monistic view (the human way of living is transcendentally constituted by one single form of life). But this is not necessarily the case; on the contrary, this intuitive scheme can hardly make sense of some seemingly intermediate positions, such as those of commentators who affirm that there is a single form of life and it is empirical (see for example Hunter), or those affirming that there are different transcendental forms of life expressed in different types of Weltbild (see Williams). This multiplicity of possible positions can be made clearer by crossing the two axes and describing the four resulting possibilities as:

1) Empirical pluralism. If forms of life are to be found on an empirical level, and if we identify them with the social and cultural features of a human society, then we can affirm that each human aggregate constitutes a form of life, if it is characterized by the existence of shared practices and a shared background of knowledge, language, know-how, history, culture. Each form of life is then a possible subject for anthropological research. Empirical pluralism can be associated, for instance, with Max Black, Naomi Scheman, Norman Malcolm.

2) Empirical monism. Form of life is identified with the buman form of life. Biology plays a very relevant role here, but human life is not confined to biology: man is "a political animal", living in society, building cities and institutions, speaking a language, holding habits, customs, traditions, culture. Man possesses what has been called a second nature. Apart from the human form of life, the world is inhabited by different animal forms of life. Empirical monism can be associated with F. M. Hunter, and for some aspects with Stanley Cavell and Newton Garver.

3) Transcendental pluralism. There can be different forms of life but each of them is transcendental: the belonging to one form of life is what provides any individual with the conditions of possibility, through which she can perceive the world and live in it. Every form of life has a language and a Weltbild, a picture of the 
world. Problems may arise when two or more different forms of life come into contact, as each culture sees the other in its own way and so potentially distorts the nature of the other. Transcendental pluralism can be associated with Nicholas Gier and Bernard Williams.

4) Transcendental monism. There is only one transcendental human form of life. Each human being possesses the same (linguistic) lenses through which she relates to the world, to other beings and to herself. Form of life, as the source of any intelligibility, is itself exempt from intelligibility: it is not possible to objectively describe it from the outside. The attempt will be that of describing it from the inside, coming into touch with its limits. This perspective can be associated with Jonathan Lear and Lynne Rudder Baker.

Although inevitably over-simplified, the four classes constitute a possible frame of reference for understanding the differences among commentators, and for making us appreciate with more precision the meaning and the extent of a cluster of problems connected with these concepts. Relativism, objectivity, communication, disagreement, social change are among them. It is not possible to deal with these enormous issues here, but a good way to handle these themes may be that of making the different perspectives just outlined work together (which does not mean mixing them up again). Acknowledging that human beings share a common ground of natural characteristics, or a common transcendental structure, may be the starting point for making subtler differences explicit, giving value and not discredit to the partiality of points of view. ${ }^{11}$ But this is only a clue for future inquiries.

Bearing in mind the four characterizations of forms of life, we can now turn back to Wittgenstein's texts, to examine not only the occurrences already seen in the PI, but also other previous and subsequent entries and related themes in this new light, and eventually to see if a conceptual development can be traced.

${ }^{11}$ Naomi Scheman's call for a transition from an epistemology of parsimony to an epistemology of largesse goes in this direction: see Scheman (1995). 


\section{Back to Wittgenstein}

As we have seen in analyzing the first occurrence of Lebensform, its immediate predecessor in the Brown Book was the word "culture", and, in connection to it, "tribe". This is a good index of the fact that Wittgenstein was not fully satisfied with the concept of culture, and felt the need to use a slightly different expression, like Lebensform. ${ }^{12}$ We can conjecture that what he was seeking was a clearer connection between culture and life, or, better said, between culture and the way life is conducted. Furthermore, this early occurrence could suggest that when he initially began to use this term, he held an anthropological point of view, which we can temporarily identify with empirical pluralism. We shall see if other pieces of evidence can support this idea.

In the notes Wittgenstein wrote on James G. Frazer's The Golden Bough, we find an expression that we can juxtapose to Lebensform, in a curious and often cited remark on "human races" compared to fleas:

(6) It was not a trivial reason, for really there can have been no reason, that prompted certain races of mankind to venerate the oak tree, but only the fact that they and the oak were united in a community of life [Lebensgemeinschaft], and thus that they arose together not by choice, but rather like the flea and the dog. (If fleas developed a rite, it would be based on the dog). (PO, 139) $)^{13}$

In this very early use of a term quite near to our Lebensform, it appears that the point of view is empirical and plural. Other occurrences of Lebensform and Lebensformen, previous to those of the PI, seem to confirm this empirical and plural standpoint:

(7) (...) I want to say: it is characteristic of our language that the foundation on which it grows consists in steady ways of living [fester Lebensformen], regular ways of acting.

Its function is determined above all by action, which it accompanies.

\footnotetext{
${ }^{12}$ On the meaning of this word in Wittgenstein's times and, particularly, on the possible sources in Wittgenstein's own readings, see the Introduction in Padilla Gálvez and Gaffal (2011).

${ }^{13}$ This remark is dated 1931 and can be found in MS 110, 298, where the expression Lebensgemeinschaft is accompanied by the insertion "Symbiose".
} 
We have an idea of which ways of living [Lebensformen] are primitive, and which could only have developed out of these. We believe that the simplest plough existed before the complicated one. (...) (PO, 397; originally in MS 119, 74v, dated 1937).

(8) Why shouldn't one form of life culminate in an utterance of belief in a Last Judgment? But I couldn't either say "Yes" or "No" to the statement that there will be such a thing. Nor "Perhaps", nor "I'm not sure" (LC: 58, dated 1938).

Now, it is important to note that Wittgenstein did not embrace an empirical approach tout court, without reflection; quite the opposite, it is likely that he deemed that these kinds of observations and remarks did not belong to any empirical science - sociology, anthropology, ethnology - but only had the methodological relevance of enabling us to see things differently, thus remaining within a philosophical perspective. This, I think, is a key point. ${ }^{14}$ In 1940 Wittgenstein noticed:

If we look at things from an ethnological point of view, does that mean that we are saying that philosophy is ethnology? No, it only means that we are taking up a position right outside so as to be able to see things more objectively. (MS 162b, 67v; later in CV, 37)

This is the reason why Wittgenstein could use real, but also counterfactual and imaginary examples: the aim is not that of stating how things are, but that of getting a deeper objectivity; where the concept of objectivity is not linked to the traditional idea of mirroring nature, or mirroring cultures and societies. "Our world looks quite different if we surround it with different possibilities", he wrote in 1937 (PO, 379). What interested him in the empirical approach, then, was its importance in "teaching us differences", 15 and in contributing to this radically new idea of objectivity, delineated through reference to a field of possibilities or potentialities. To put it differently, he was interested in a conceptual, logical, grammatical inquiry, not alien to ethical aims, and anthropological remarks were a methodological instrument for this kind of philosophical work (see RPP II 308-310).

\footnotetext{
${ }^{14}$ Cf. Andronico (1988); Whiterspoon (2003).

15 "I'll teach you differences" is the quotation from King Lear that Wittgenstein once thought of using as a motto for the PI; cf. Rhees $(1981,171)$.
} 
Let us proceed with other quotes.

The term Lebensform can be found, later, in MS 165, dated 19411944 , in connection with language and with foreign countries.

(9) Were we to arrive in a foreign country, with a foreign language and foreign customs, it could be easy in some cases to find a form of language and form of life [Sprach- und Lebensform] which we should define giving orders and following orders; or maybe they would not possess a form of language and of life corresponding to our giving orders etc. And there may be a people which does not hold a form of life corresponding to our greeting. (MS 165,110)

In a comment dated 1944, concerning a pupil learning to follow a rule, we find the combination of forms of language and of life again:

(10) And if the pupil reacts to it thus and thus; he possesses the rule inwardly.

But this is important, namely that this reaction, which is our guarantee of understanding, presupposes as a surrounding particular circumstances, particular forms of life and speech [Lebens- und Sprachformen]. (As there is no such thing as a facial expression without a face.)

(This is an important movement of thought.) (RFM, part VII: 47; cf. MS 124, 150 and MS 127, 92)

Wittgenstein himself stresses the importance of this observation, which is here connected to rules and mathematics. Rules and mathematics constitute also the context of the remark of PPF, already seen, on "the given" (our fifth entry). But in its previous formulation, as we noticed, it had a more practical accent, and in that context "forms of life" had as a variant "facts of living": "facts" has an empirical connotation which the use of Lebensformen is probably meant to avoid. Wittgenstein is moving towards a more formal and maybe transcendental stance, which brings into prominence the instinctive and sometimes animal character of the behaviour, actions and reactions that we can recognize as belonging to our form of life. In other words, I think that the writings belonging to the last years of his life are reminiscent of the transcendental flavour of the Tractatus, but from within a pragmatic, in a sense even pragmatist perspective (Boncompagni 2013 \& 
Forthcoming). I will try to clarify this assumption by examining the last occurrences of Lebensform in his work.

(11) One might say: "I know' expresses comfortable certainty, not the certainty that is still struggling."

Now I would like to regard this certainty, not as something akin to hastiness or superficiality, but as a form of life [Lebensform]. (That is very badly expressed and probably badly thought as well.)

But that means I want to conceive it as something that lies beyond being justified or unjustified; as it were, as something animal.(OC 357359, from MS $175,55 \mathrm{v}, 56 \mathrm{r})^{16}$.

These paragraphs of On Certainty, written in 1951, testify both Wittgenstein's dissatisfaction with the way he describes forms of life, and the relevance of this theme, deeply bound to that of certainty. Here certainty, which has to do with the way we act, much more than with the way we think, belongs to every human being, making Wittgenstein incline toward a monistic view. ${ }^{17}$ This certainty is neither justified nor unjustified because it is precisely that which constitutes the ground, or better said the background, of any justification. And this background, no wonder, is almost impossible to describe (hence the dissatisfaction) (Cf. CV, 16; RPP II 624, 625, 629; OC 94, 461).

The pragmatic background of our acting, thinking and speaking, making our acting, thinking and speaking possible, belongs to what cannot be said, but only shown (Moyal-Sharrock 2003: 136; Boncompagni 2014). It possesses at the same time a logic and pragmatic character: "Am I not getting closer and closer to saying that in the end logic cannot be described?", Wittgenstein asks himself in 1951, and adds, echoing in some respects the Tractatus: "You must look at the practice of language, then you will see it" (OC 501).

\footnotetext{
${ }^{16}$ It may be noticed that in MS 175 Wittgenstein, after writing the remark, put the article "eine", of "eine Lebensform", in brackets. The German text of OC preserves them, while the English translation omits them.

${ }^{17}$ This is compatible, anyway, with the acknowledgment that different cultures decline our common Lebensform in different ways and it may be difficult for one culture, or one age, to understand another. Cf. CV, 87: "One age misunderstands another; and a petty age misunderstands all the others in its own nasty ways" (remark dated 1950).
} 
The difficulty of speaking about our form of life is confirmed by a last entry, written one month after the cited passages from OC, and, curiously, dealing with uncertainty, instead of certainty:

(12) And now the question remains whether we would give up our language-game which rests on 'imponderable evidence' and frequently leads to uncertainty, if it were possible to exchange it for a more exact one which by and large would have similar consequences. For instance, we could work with a mechanical "lie detector" and redefine a lie as that which causes a deflection on the lie detector.

So the question is: Would we change our way of living [Lebensform] if this or that were provided for us? - And how could I answer that? (MS 176, 51v, published in LWP II, 95)

How could I answer such a question? How could I place myself outside my form of life, my Weltbild, and decide whether a different form of life would be better? Clearly, there's no way of stepping outside, as the limits of my Weltbild mean the limits of my $W$ elt. But here, again, in my view, Wittgenstein is not making a transcendental claim in the traditional sense. His remarks about the impossibility of stepping outside the human Weltbild and form of life are not theoretical claims, but are more akin to gestures, ways of showing the reader that it is her life itself that gives sense to her words and her actions. Just as Wittgenstein did not embrace an empirical standpoint when using the conceptual tool of forms of life emphasizing its empirical aspect, he does not embrace a transcendental standpoint now, when using the same conceptual tool emphasizing its transcendental aspect. In both cases, his work on forms of life is instrumental with respect to the ends of philosophical activity.

\section{Concluding remarks}

We have examined Wittgenstein's concept of Lebensform, first by analyzing the five occurrences of the term in PI, and tracing them back to the Nachlass; then by looking at the secondary literature, and systematizing the authors in a classification based on the empirical vs. transcendental and the monistic vs. pluralistic axes of debate. This equipped us with a useful schema, thanks to which we could have a sort of synoptic representation of the range of 
possible interpretations of forms of life, as well as of the main issues and problems that they are connected to. Finally we have gone back to Wittgenstein's texts and concluded with an evolutionary reading, according to which Wittgenstein's early use of the concept Lebensform, connected to an empirical and pluralistic view, eventually resulted in a monistic and transcendental view in his last writings. The later perspective holds something in common with the Tractatus, but is embedded in a pragmatic approach. In conclusion, what I am interested in underlining, is that throughout this process the methodological standpoint prevented Wittgenstein from espousing a fully-fledged anthropological stance, as well as a fully-fledged transcendentalist system of philosophy. In the light of Wittgenstein's general attitude to philosophy, intended as a clarifying and therapeutic activity, I believe that his idea of Lebensform was meant to enlighten the importance of directing our gaze towards the way we live, the way others live, the way imaginary others live, the way we may live. This is neither a historical-anthropological investigation, nor a metaphysics of life (Perissinotto 1991: 218; Medina 2004: 89), but a grammatical exercise regarding limits: the limits of our language, of our form of life, and of our inquiry. ${ }^{18}$ Wittgenstein's work is, ultimately, a cultivation of our sight, primarily addressed to the training of our attention and capacity to see differences. ${ }^{19}$

\section{References}

Agam-Segal, R., 2009. "Contours and Barriers: What is it to Draw the Limits of Moral Language?”. Philosophy, 84:4, pp. 549-570.

Andronico, M., 1998. Antropologia e metodo morfologico. Studio su Wittgenstein. Napoli: La Città del Sole.

Biancini, P., 2011. "From Umgebung to Form of Life: a Genealogical Reading". In: J. Padilla Galvez, M. Gaffal, eds. 2011. Forms of Life and Language Games. Heusenstamm: Ontos Verlag.

\footnotetext{
${ }^{18}$ On the concept of limit, especially in ethics, cf. Agam-Segal (2009).

${ }^{19}$ A first draft of this paper was given at the conference In Wittgenstein's Footsteps, held in Reykjavik in 2012. I wish to thank the audience for their insightful comments, and particularly Reshef Agam-Segal for our follow-up email conversation.
} 
Black, M., 1978. “Lebensformen and Sprachspiel in Wittgenstein's later work". In: E. Leinfellner et al., eds. 1978. Wittgenstein and his Impact on Contemporary Philosophy. Proceedings of the 2 nd International Wittgenstein Symposium. Wien: Holder-Pichler-Tempsy.

Boncompagni, A., 2013. “The Pragmatic Maxim in Wittgenstein’s On Certainty". In: A. Coliva, D. Moyal-Sharrock, V.A. Munz, eds. 2013. Mind, Language and Action. Papers of the 36th International Wittgenstein Symposium. Kirchberg am Wechsel: Austrian Wittgenstein Society.

Boncompagni, A., 2014. "On trying to say what 'goes without saying'. Wittgenstein on Certainty and Ineffability". Ricerche di Pedagogia e Didattica - Journal of Theories and Research in Education, 9:1, pp. 51-68.

Boncompagni, A., (Forthcoming). Wittgenstein and Pragmatism. Basingstoke: Palgrave Macmillan.

Cavell, S., 1979. The Claim of Reason. Wittgenstein, Scepticism, Morality, and Tragedy. Oxford: Oxford University Press.

Cavell, S., 1989. This New yet Unapproachable America. Lectures after Emerson after Wittgenstein. Albuquerque, NM: Living Batch Press.

Christensen, A.M., 2011. “What matters to us?’ Wittgenstein's Weltbild, Rock and Sand, Men and Women". Humana.Mente Journal of Philosophical Studies", 18, pp. 141-162.

Cerbone, D., 2011. "Wittgenstein and Idealism”. In: O. Kuusela, M. McGinn, M., eds. 2011. The Oxford Handbook of Wittgenstein, Oxford: Oxford University Press.

Emmett, K., 1990. "Forms of Life". Philosophical Investigations, 13:3, pp. 213231.

Fischer, H.R., 1987. Sprache und Lebensform. Wittgenstein über Frend und die Geisteskrankheit. Frankfurt am Main: Athenäum.

Garver, N., 1994a. This Complicated Form of Life. Essays on Wittgenstein. Chicago and La Salle, IL: Open Court.

Garver, N., 1994b. "Naturalism and Transcendentality: The Case of 'Form of Life". In: S. Teghrarian, ed. 1994. Wittgenstein and Contemporary Philosophy. Bristol: Thoemmes Press.

Gellner, E., 1985. Relativism and the Social Sciences. Cambridge: Cambridge University Press.

Gellner, E., 1992. Reason and Culture. Oxford: Blackwell.

Gier, N., 1980. "Wittgenstein and Forms of Life". Philosophy of the Social Sciences, 10:3, pp. 241-258.

Hertzberg, L., 1980. "Winch on Social Interpretation". Philosophy of the Social Sciences, 10:2, pp. 151-171.

Hunter, J.F.M., 1968. “Forms of Life in Wittgenstein's Philosophical Investigations". American Philosophical Quarterly, 4:4, pp. 233-243.

Lear, J., 1984. "The Disappearing 'We"'. Proceedings of the Aristotelian Society, Supplementary Volumes, 58, pp. 219-242. 
Lear, J., 1986. “Transcendental Anthropology”. In: P. Pettit, J. McDowell, eds. 1986. Subject, Thought, and Context. Oxford: Clarendon Press.

Malcolm, N., 1966. “Wittgenstein's Philosophical Investigations”. In: G. Pincher, ed. Wittgenstein. The Philosophical Investigations. New York: Anchor Books.

Malcolm, N., 1982. "Wittgenstein and Idealism”. In: G. Vesey, ed. 1982. Idealism. Past and Present. Cambridge: Cambridge University Press.

Malcolm, N., 1986. Nothing is Hidden. Oxford: Blackwell.

Medina, J. 2004 “Wittgenstein's Social Naturalism”. In: D. Moyal-Sharrock, ed. 2004. The Third Wittgenstein. Aldershot: Ashgate.

Moyal-Sharrock, D., 2003. "Logic in Action: Wittgenstein's Logical Pragmatism and the Impotence of Scepticism". Philosophical Investigations, 26:2, pp. 125-148.

Moyal-Sharrock, D., 2004. Understanding Wittgenstein's On Certainty. Basingstoke: Macmillan.

Padilla Gálvez, J., Gaffal, M., eds. 2011. Forms of Life and Language Games. Heusenstamm: Ontos Verlag.

Perissinotto, L. 1991. Logica e immagine del mondo. Studio su Über Gewissheit. Milan: Guerini.

Pichler, A., Smith, D., 2013. "A List of Correspondences between Wittgenstein TS-310 and MS 115ii". In: A. Coliva, D. Moyal-Sharrock, V.A. Munz, eds. Mind, Language and Action. Papers of the 36th International Wittgenstein Symposium, Kirchberg am Wechsel: Austrian Wittgenstein Society.

Pleasants, N., 2000. "Winch and Wittgenstein on Understanding Ourselves Critically: Descriptive not Metaphysical”. Inquiry, 43:3, pp. 289-318.

Rhees, R., ed. 1981. Recollections of Wittgenstein. Oxford: Blackwell.

Rudder Baker, L., 1984. "On the Very Idea of a Form of Life". Inquiry, 27, pp. 277-289.

Scheman, N., 1995. "Feeling Our Way toward Moral Objectivity". In: A. Clark et al., eds. 1995. Mind and Morals, Cambridge, MA: MIT Press.

Scheman, N., 1996. "Forms of Life: Mapping the Rough Ground". In: H. Sluga, D.G. Stern, eds. 1996. The Cambridge Companion to Wittgenstein. Cambridge: Cambridge University Press.

Williams, B. 1974. "Wittgenstein and Idealism”. In: G. Vesey, ed. 1974. Understanding Wittgenstein. London: Macmillan.

Winch, P., 1958. The Idea of a Social Science and its Relation to Philosophy. London: Routledge.

Winch, P., 1964. "Understanding a Primitive Society". American Philosophical Quarterly, 1:4, pp. 307-324.

Witherspoon, E., 2003. "Conventions and Forms of Life". In: F.F. Schmitt, ed. 2003. Socializing Metaphysics. The Nature of Social Reality, Oxford: Rowman \& Littlefield. 
Wittgenstein, L., 1969. The Blue and Brown Books. Oxford: Blackwell [BB]

Wittgenstein, L., 1975. On Certainty. Oxford: Blackwell [OC]

Wittgenstein, L., 1978. Remarks on the Foundations of Mathematics. Oxford:

Blackwell [RFM]

Wittgenstein, L., 1980. Culture and Value. Oxford: Blackwell [CV]

Wittgenstein, L., 1980. Remarks on the Philosophy of Psychology. Oxford:

Blackwell [RPP]

Wittgenstein, L., 1992. Last Writings on the Philosophy of Psychology. Oxford:

Blackwell [LWP]

Wittgenstein, L., 1993. Philosophical Occasions 1912-1951. Indianapolis: Hackett [PO]

Wittgenstein, L., 2000. Wittgenstein's Nachlass. The Bergen Electronic Edition.

Oxford: Oxford University Press [BEE]

Wittgenstein, L., 2007. Lectures and Conversations on Aesthetics, Psychology and

Religious Belief. Berkeley: University of California Press [LC]

Wittgenstein, L., 2009. Philosophical Investigations. Oxford: Wiley-Blackwell [PI, $\mathrm{PPF}]$

\section{Biographical Note}

Anna Boncompagni works mainly on Ludwig Wittgenstein. Her research focuses on the pragmatic aspects of his thought and on his complex relationship with the pragmatist tradition. She completed her $\mathrm{PhD}$ at the University of Roma Tre, Italy and is the author of a monograph on the importance of 'seeing' in Wittgenstein's thought (Wittgenstein. Lo sguardo e il limite, 2012), and of articles in journals and edited volumes on Wittgenstein, William James, Frank Ramsey, and Charles S. Peirce. She is presently working on a volume on Wittgenstein and pragmatism, to be published in 2016 (Palgrave Macmillan). 